
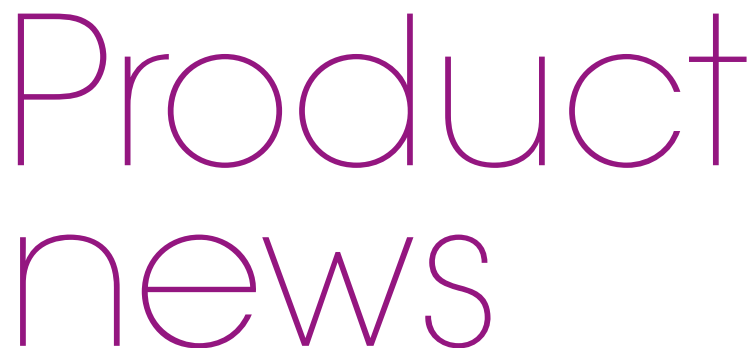

\title{
LAUNCH OF ONLINE REVIEW SOFTWARE THIS MONTH
}

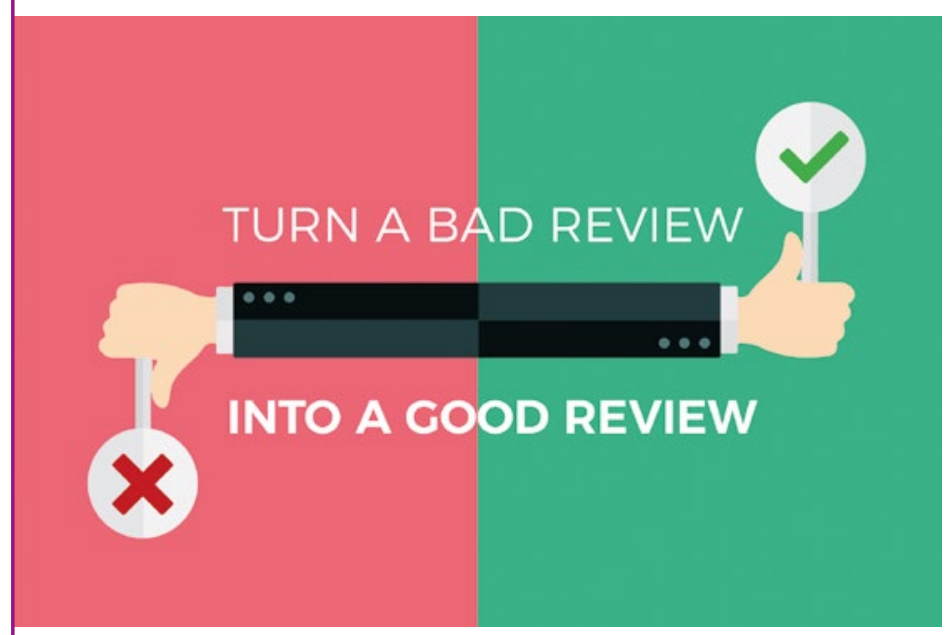

The company is inviting delegates to come to the launch and hear its 15-minute talk repeated throughout both days of the show, with the dental marketing experts discussing how to deal with negative reviews. The talks

Dental Design is launching its new review management system - EasyReview - at the British Dental Conference and Dentistry Show 2019, co-located with the Dental Technology Showcase. will take place at stand D4.

To find out more about Dental Design's services, visit: https://dental-design-products. co.uk/ or email enquiries@dental-design. co.uk or call 01202677277.

\section{NEW TREATMENT CO-ORDINATOR ROLE FOR LLOC}

Due to the popularity of treatment at the London Lingual Orthodontic Clinic in London's West End, a new role has been introduced. Renata Sakalauskiene

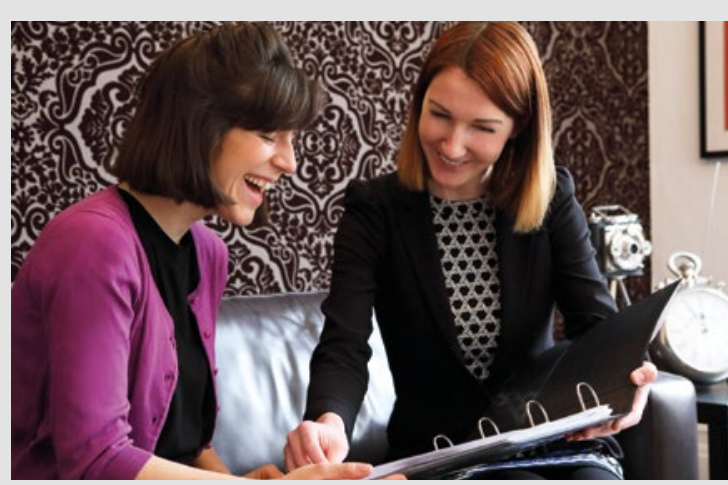

(pictured), a qualified dental nurse, has been appointed treatment co-ordinator and is available to provide complimentary consultations. During a half hour appointment she will explain orthodontic options at the clinic, provide a tour and answer any questions. The first clinic to be dedicated to lingual braces, the founder, Asif Chatoo, is the only UK orthodontist accredited by both the World and European Lingual Societies. To find out more, visit: www. londonlingualbraces.com.

\section{TOUCHSCREEN X-RAYS FOR EASE OF USE}

The new Belmont Touch X-ray system is compatible with any type of digital imaging system. Not only does it reduce the soft $\mathrm{x}$-rays absorbed by the tissues, making it safer and more reassuring for patients, but the tube voltage, current and exposure time can all be selected according to the individual clinical need, helping to avoid unnecessary exposure to radiation.

Offering a minimum exposure time of just 0.01 seconds, the Belmont Touch preprogrammed timer is selectable for digital systems and two different types of films.

A total of 16 film speeds are available and the lightweight, compact, easy to hold tube head enables the operator to align the tube accurately every time for re-producible, high contrast, crisp radiographs with excellent image quality.

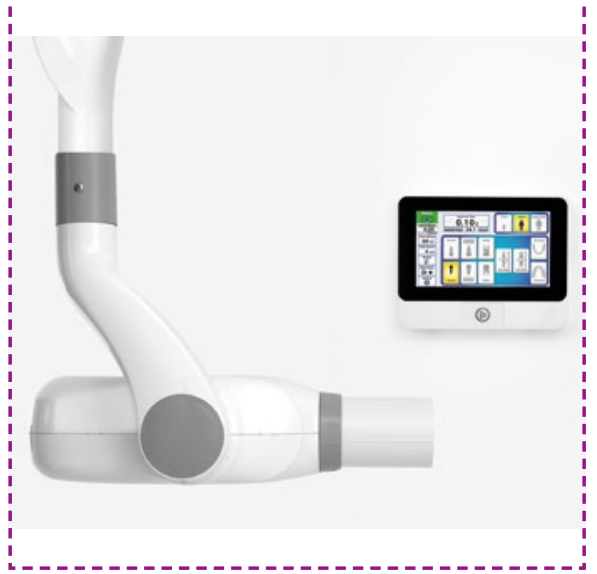

If you would like to promote your products or services direct to the dental industry in BDJ Team, call Andy May on 02078434785 or emaila.may@nature.com. 